\title{
Exercise Guidelines for Pregnant Women
}

\author{
SeonAe Yeo
}

\begin{abstract}
Despite remarkable improvements in high technologies and an increase in the number of studies related to exercise for pregnant women, the guidelines for maternal exercise remain contradictory. The effects of exercise in pregnant women and cardiovascular modifications due to pregnancy, and effects of maternal exercise on the fetal environment, including uterine and umbilical hemodynamic changes, are reviewed. Suggested future directions in this area of nursing science are discussed.
\end{abstract}

[Keywords: exercise; pregnancy;women's health]

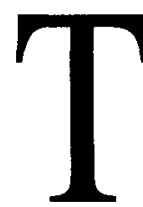

he growing participation by childbearing women in physical fitness activities has encouraged researchers to study the effect of exercise during pregnancy (Cunningham \& Cantu, 1990; Fagard, 1985; Gledhill, 1985; Lotgering, Gilbert, \& Longo, 1985; Sady, et al., 1989; Sady, et al., 1988). Despite remarkable improvements in technologies that permit indirect measurement of maternal-fetal hemodynamic changes, and an increase in the number of studies related to pregnant women's exercise, the available guidelines for maternal exercise are often contradictory. With a limited scientific basis, attempts are made to delineate specific exercise guidelines for promoting maternal health while decreasing fetal risk (American College of Obstetricians and Gynecologists [ACOG], 1985; American College of Sports Medicine [ASCM], 1991; Caldwell \& Jopke, 1985; Fitness Canada, 1982; Fitness Ontario, 1983).

Theoretically, the pregnancy outcomes that could be related to maternal exercise are many and include the following: spontaneous abortion, uterine bleeding, abruptio placentae, premature labor, premature rupture of membranes, cord prolapse, malpresentation, operative or instrumental delivery, pregnancyinduced hypertension, congenital anomalies, intrauterine growth retardation, fetal distress, meconium aspiration, stillbirth, low Apgar scores, neonatal adaptation difficulties, long labor, and long postpartum recovery (Artal-Mittelmark et al., 1991). However, the literature does not establish an association between these complications and maternal exercise, nor does it refute an association. Therefore these questions remain: Should women modify their exercise regimens when they are pregnant? Should nurses encourage pregnant women to exercise? What are the long-term effects of either increased or decreased exercise during pregnancy on the psychosocial well-being of women and their infants?

The available guidelines may be too conservative or too aggressive depending on a woman's age, aerobic fitness level, or type of exercise.

\section{Effects of Exercise on Pregnant Women}

Exercise is a physiologic stressor and, as such, requires major homeostatic adjustments in all organ functions if the exercise is to be continued (Wiswell, 1991). At the onset of exercise, cardiovascular changes are initiated from nerve centers above the medullary region. Chemical, neural, and hormonal adjustments cause a significant increase in the rate and pumping strength of the heart, as well as predictable alterations in regional blood flow that are proportional to exercise intensity. As exercise continues, sympathetic cholinergic outflow, in addition to local metabolic factors that act on chemosensitive nerves and directly on the blood vessels, causes dilation of resistance vessels in active muscles. This reduced peripheral resistance permits the exercising muscles to accommodate greater blood flow. As exercise continues, there are constrictor adjustments in less active tissues. Thus, an adequate perfusion pressure can be maintained even with the large dilatation of the muscle's vessels. The constrictor action provides for appropriate redistribution of blood to meet the metabolic requirements of working muscles and less active tissues (McArdle, Katch, \& Katch, 1986).

Although several studies have assessed the fitness potential of nonpregnant athletic women (Ballor, Beque, \& Katch, 1989; Brown, Harrower, \& Deeter, 1972; Brown \& Wilmore, 1974; Drinkwater, 1973; Erdely, 1962; Plowman, 1974), the specific effect of exercise on pregnant women is poorly understood. Statements about the exercise potential of childbearing women have been based largely on studies using nonpregnant subjects. To understand the influence of exercise on maternal and fetal

\footnotetext{
SeonAe Yeo, RN, PhD, Rho, is Assistant Professor of Parent Child Nursing, University of Michigan School of Nursing, Ann Arbor, Michigan. The author acknowledges Jean Goeppinger, Nancy Reame, Debbie Oakley, Carollyn Sampselle, and Robert Hayashi for their advice and support Correspondence to University of Michigan, School of Nursing, 400 North Ingalls Street, Ann Arbor, MI 48109-0482.

Accepted for publication September 24, 1993.
} 
health, it is essential to assess not only the exercise demands in female physiology, but also the additional physiological burdens of pregnancy.

Pregnancy is a high-flow, low-resistance state of cardiovascular homeostasis associated with hemodynamic changes of an exceptional magnitude. Cardiac output increases in early pregnancy reaching a peak of $30 \%$ to $50 \%$ above nonpregnant values at 20 to 24 weeks of gestation. This increment in maternal cardiac output is accounted for by a dramatic increase in uterine blood flow to satisfy the metabolic demands of the fetus and by a significant increase in blood flow to certain nonreproductive organs (Itskovitz, 1987). Because of the physiologic changes that occur normally during pregnancy, exercise may impose significant stress on the pregnant woman. The metabolic demands of pregnancy affect many changes in resting maternal physiologic status. Therefore, it is important to examine whether the additional stress of exercise induces adjustments that might exceed the threshold of safety for mother and fetus (Wallace \& Wiswell, 1991).

Inconclusive information about the adaptation of the circulatory system of a pregnant woman to exercise stress suggests the following:

1. Resting heart rates and heart rates at lower exercise intensities are higher during pregnancy, which reduces the available margin of increase during exercise. Heart rate recovery after exercise increases as pregnancy progresses, while physical recovery time indicates no change (Bonds \& Papadoupofflos, 1985; Wallace $\&$ Wiswell, 1991). These observations suggest that exercise capacity may decrease during pregnancy.

2. An exercise-induced increase in cardiac output and stroke volume for moderate exercise decreases progressively throughout pregnancy, suggesting that pregnant women may be less responsive to exercise than nonpregnant women (Guzman \& Caplan, 1970; Wallace \& Wiswell, 1991). At the same time, several studies report that the increase in oxygen uptake by tissues $\left(\mathrm{VO}_{2}\right)$ at any given heart rate increment for pregnant women exceeds that of nonpregnant women (Sady, et al., 1989; Wiswell, Artal-Mittelmark, Romen, Kammula, \& Dorey, 1985) contradicting the findings of previous studies.

3. Moderate exercise is not accompanied by a change in the arterial-venous oxygen concentration difference (A-V difference). The A-V difference decreases in pregnancy because of increased blood volume. This finding suggests that exercise may not be as physiologically stressful in pregnant women as in nonpregnant women (Guzman \& Caplan, 1970).

These conflicting findings suggest that the potential exercise capacity of pregnant women may decrease during gestation while the physiologic effect of exercise on the body may or may not change during pregnancy. It must be noted, however, that these findings were drawn from studies with several methodologic weaknesses such as the inclusion of nonpregnant subjects, small sample sizes, cross-sectional design, or the use of low exercise intensity (heart rate of $108 \mathrm{bpm}$ ) without a description of work load. It is imperative that more data from studies of pregnant women be obtained and used as the foundation for exercise guidelines.

\section{Effects of Exercise on Fetal Environment}

Two potential mechanisms that may have a detrimental effect on a fetus during maternal exercise are hyperthermia and impaired uterine and umbilical blood flow (Artal-Mittelmark \& Posner, 1991).

Hyperthermia. Although based on animal studies, the only confirmed threat to fetal safety from maternal exercise is heat stress (hyperthermia). The ACOG guidelines (1985) suggest limiting the core temperature during exercise to $38^{\circ} \mathrm{C}$, yet they do not specify the means of obtaining the measurement. Research with animals suggests that there may be adverse consequences for the fetus should the maternal core temperature reach $39^{\circ} \mathrm{C}$ or above (Bonds \& Papadoupoulos, 1985; Edward, 1986; Miller, Smith, \& Shepard, 1978; Shiota, 1982). These studies indicate an association between hyperthermia, defects of the fetus' central nervous system (anencephaly, encephalocele, and spina bifida), and decreased uterine blood flow.

Closure of the anterior neuropore occurs at about 25 days after conception and the posterior neuropore at 27 days, although these can vary by a day or two (Moore, 1988). Potential teratogenic effects are most likely to occur during the first 26 to 30 days after conception or 50 days from the last menstrual period (Drinkwater \& Artal-Mittelmark, 1991). Heat stress is also associated with reduced uterine blood flow (Bonds \& Papadoupoulos, 1985). It is generally recommended that maternal body temperature remain under $39^{\circ} \mathrm{C}$ throughout pregnancy for the well-being of both mother and fetus. But this temperature threshold is founded on estimation rather than scientific knowledge. This question is complicated by uncertainty about the definition of core temperature and methods to measure it. According to Guyton (1991), core temperature, sometimes called body temperature, refers to the deep tissue temperature, which remain consistent; whereas skin temperature rises and falls with the temperature of the surrounding external environment. The rectum, esophagus, pulmonary artery, and ear canal are often used to determine core temperature. Human body temperature varies by more than $1.5^{\circ} \mathrm{C}$ depending on the site where the measurement is taken (Milewski, Ferguson, \& Terndrup, 1991). A rectal temperature is generally higher than an ear, pulmonary artery, or esophageal temperature, although all are referred to as core temperature. For example, while one core temperature site is $38^{\circ} \mathrm{C}$, the rectal temperature could be $39.15^{\circ} \mathrm{C}$, exceeding the currently accepted safety limit for pregnant women. Given the fact that rectal temperature is higher than body temperatures at other sites and given its proximity to the fetus, a conservative guideline that rectal temperature not exceed $38^{\circ} \mathrm{C}$ may be best.

Measurement of rectal temperature at home is usually obtained by the use of a glass mercury thermometer. This method, however, may not appeal to pregnant women, in spite of the relatively short period of about one minute required for the measurement. Currently, tympanic membrane thermometers, which require only a few seconds for measuring a temperature and no particular need for privacy, are available for home use. However, none of the currently available brands have been validated with pregnant women.

Uterine Circulation and Exercise. Theoretically, there are no continuous, direct vascular communications between the fetal 
blood contained in the fetal capillaries of the chorionic villi in the intravillous space and the maternal blood in the intervillous space. The intervillous space is the biologic compartment of transfer; the maternal blood in this compartment directly bathes the chorionic villi (Cunningham, MacDonald, \& Gant, 1989). In the intervillous space, substances such as oxygen and nutrients pass from mother to fetus while metabolic waste products are transferred from fetus to mother. Therefore, acute reduction in uterine blood flow does not cause acute reduction in fetoplacental blood flow, but it could lead to fetal hypoxia. Initially, the fetus seems to respond to hypoxia with tachycardia and, when prolonged, with bradycardia (Artal-Mittelmark \& Posner, 1991). Because of the absence of direct vessel communication, uterine artery blood flow will be expected to change, whereas umbilical artery blood flow will remain unchanged.

Animal studies have indicated that exercise of moderate to strenuous intensity causes a maximum uterine blood flow reduction of $40 \%$ (Lotgering, Gilbert, \& Longo, 1984, 1985) and that exercise-induced changes are dose-responsive. (Bonds \& Papadoupoulos, 1985; Brinkman, 1990; Chandler \& Bell, 1981; Hohimer, Bissonnette, Metcalfe, \& McKean, 1984; Lotgering, Gilbert, \& Longo, 1984, 1985). Only limited information is available, however, about human fetal and maternal hemodynamic responses to exercise during pregnancy. The findings are conflicting because of small sample sizes, confounding factors, and shortcomings in study designs. Furthermore, hemodynamic responses involve both uterine and umbilical blood circulation as two systems are essentially independent of one another. Thus far, studies have not investigated both systems simultaneously.

In human subjects, findings regarding uterine blood flow and exercise have been inconsistent (Baumann, Huch, \& Huch, 1989; Moore, Jarrett, \& Bendick, 1988; Morrow, Knox, \& Bull, 1989; Rauramo \& Forss, 1988; Steegers, et al., 1988; Veille, Bacevice, Wilson, Janos, \& Hellerstein, 1989). In 1956, Morris, Osborn, Wright, and Hart reported decreased uterine blood flow during short-term bicycle exercise by measuring the clearance time of radioactive sodium $\left(\mathrm{N}^{24}\right)$ injected into the myometrium. In 1983, Campbell and colleagues (1983) first reported a non-invasive technique for assessing utero-placental blood flow by Doppler waveform. In 1988 and 1990, several studies using Doppler waveform (Baumann, Huch, \& Huch, 1989; Hume, et al., 1990; Moore, 1988; Morrow, Knox, \& Bull, 1989; Steegers, et al., 1988) and one study using intravenous Xenon technique (Rauramo \& Forss, 1988) reported exercise-induced changes in uterine and/or umbilical arterial and/or intervillous placental blood flow.

Whereas four studies reported no significant changes in hemodynamic condition after exercise (Baumann, Huch, \& Huch, 1989; Moore, 1988; Rauramo \& Forss, 1988; Steegers et al., 1988), one study by Morrow indicated that vascular resistance increased after exercise (Morrow, Knox, \& Bull, 1989). These four studies examined uterine artery blood flow, its flow velocity, and intervillous vascular beds flow in the placenta and found no significant change due to exercise. Morrow's study, on the other hand, reported a significant increase in vascular resistance at uterine arteries. The validity of the Morrow study, however, was questioned by Clapp (1990) who challenged the study's imprecise data collection and ambiguous theories of vascular resistance and uterine artery systolic/diastolic flow rate (A/B ratio). Clapp postulated that uterine vascular resistance would decrease or remain unchanged coupled with an increase in A/B ratio (Clapp, 1990).

Umbilical Blood Circulation and Exercise. Inconsistencies among the findings are even more notable in regard to umbilical hemodynamic changes induced by maternal exercise. Two studies found no $\mathrm{A} / \mathrm{B}$ ratio changes immediately after exercise (Morrow, Knox, \& Bull, 1989; Veille, Bacevice, Wilson, Janos, \& Hellerstein, 1989). Furthermore, 3 out of 18 subjects in the Veille study (1989) showed a significant increase in the $\mathrm{A} / \mathrm{B}$ ratio $(p<.05)$, which the authors related to fetal bradycardia occurring 1 minute after exercise.

These inconclusive results may stem from small sample sizes and relatively low exercise intensities, in addition to the complexity of understanding an indirect measure, the Doppler waveform. Although the research by Baumann, Huch, and Huch, (1989) reported significant decreases in both the Resistance Index and Pulsatility Index, suggesting less umbilical blood flow available for the fetus, only 13 subjects were studied. The exercise intensities varied from a low maternal heart rate of less than $105 \mathrm{bpm}$ to a maximum oxygen uptake of approximately $85 \%$. While Morrow and colleagues (1989) used the lowest exercise intensity among the four studies and Veille and colleagues (1989) applied the highest intensity (85\% max $\mathrm{VO}_{2}$ ), both reported that no changes occurred in umbilical artery blood flow velocity and waveform. Both studies applied cross-sectional designs with small sample sizes of less than 20 subjects (Morrow, Knox, \& Bull, 1989; Veille, Bacevice, Wilson, Janos, \& Hellerstein, 1989).

Methodologic Problems in the Assessment of Hemodynamic Changes. Although measures of the effect of exercise on the pregnant woman are relatively well established, it is difficult to assess the effect of maternal exercise on the fetus.

Doppler velocimetry is widely accepted as an indirect measure to assess utero-placental and fetal hemodynamics during exercise. Doppler ultrasound detects the movement of red blood cells in vessels and is used to assess blood flow in maternal and fetal vessels (Cunningham, MacDonald, \& Gant, 1989; Erskine \& Ritchie, 1985). Although the method is relatively simple, determination of absolute blood flow with this method involves inherent measurement complexity (Erskine \& Ritchie, 1985). Doppler studies generate data that is expressed in waveforms, graphic recordings from the blood vessel being examined. Waveforms are analyzed and described by several measurements or indices. Waveform indices do not measure physical quantities, and errors in the difference between measured and true values cannot be calculated (Thompson, Trudinger, \& Cook, 1988). Inaccuracies in the estimation of true waveform dimensions often lead to variation, or errors, in the values of the indices calculated from them, and are of concern. While useful, Doppler ultrasound provides very indirect and imprecise information about umbilical hemodynamics.

Scope of Current Guidelines. Despite methodologic advances assessing hemodynamic changes, current research does not provide unequivocal answers to questions about a pregnant 


\section{Table 1: Comparison of ACOG and ACSM Guidelines for Exercise During Pregnancy.}

\begin{tabular}{|c|c|c|}
\hline & ACOG Guidelines & ACSM Guidelines \\
\hline Intensity & $140 \mathrm{bpm} *$ & 12.14 Borg scale \\
\hline Duration & No more than $15 \mathrm{~min}$. & $15.30 \mathrm{~min}$. \\
\hline Frequency & No recommendation & 3-5 timestweek \\
\hline Position & No suprine position after 4 months & $\begin{array}{l}\text { No supine position } \\
\text { after } 4 \text { months }\end{array}$ \\
\hline Mode & $\begin{array}{l}\text { Avoid exercises that employ the Valsalva } \\
\text { maneuver }\end{array}$ & $\begin{array}{l}\text { Non-weight bearing } \\
\text { exercise }\end{array}$ \\
\hline Body temperature & $\begin{array}{l}\text { Maternal core temperature should not } \\
\text { exceed } 38^{\circ} \mathrm{C}\end{array}$ & No recommendation \\
\hline
\end{tabular}

\footnotetext{
Note: The data in column 1 is from:

American College of Obstetrics and Gynecologists. (1985). Exercise during pregnancy and the postnatal period. In ACOC Technical Bulletin: Women and Exercise (No. B7). Washington, DC: ACOC.

The data in Column 2 is from:

Pate, R.R. et al. (1991). Exercise prescription for special populations. In American Colley of Sports Medicine, Guidelines for Exercise Testing and Presciption (4th ed.) Philadelphia: Lea \& Febiger.

- ACOC withdrew this limitation in February 1994.
}

woman's exercise and its effect on the fetal environment. Hence, the existing home exercise guidelines for pregnant women are founded on estimation rather than on a scientific understanding of homeostatic adaptations. The ACOG guidelines are considered conservative and based upon a worst-case clinical scenario. The conservative nature of the recommendations has led to criticism from exercise physiologists who believe that the guidelines tend to discourage exercise, which has led to the development of two sets of contradictory guidelines.

In the United States, differing sets of guidelines have been developed by ACOG and ACSM to delineate exercise intensity and indices for pregnant women (Table 1). In general, the guidelines of ACSM are believed to be more vigorous concerning intensity and duration than those of ACOG.

ACOG's guidelines specify a target heart rate $(140 \mathrm{bpm})$ whereas ACSM's apply one's perception of exertion (Borg's scale 12-14). Since initial publication of the guidelines by ACOG in 1985 , concern has been expressed that a maximum heart rate of $140 \mathrm{bpm}$ is not sufficient to achieve cardiovascular fitness (ArtalMittelmark, Wiswell, Drinkwater, \& Jones-Repovich, 1991). Several studies have shown that the linear relationship between $\mathrm{VO}_{2}$ and heart rate established for nonpregnant women differs during pregnancy; the increase in $\mathrm{VO}_{2}$ at any given heart-rate increment in pregnant women exceeds that in nonpregnant women (Sady, et al., 1989; Wiswell, Artal-Mittelmark, Romen, Kammula, \& Dorey, 1985), presumably because of the added oxygen uptake by the fetus. The $\mathrm{VO}_{2}$ increases with gestational age of the fetus. The age of the mother adds an additional variable, because maximum heart rate decreases with age. Setting the limit of the maternal heart rate at $140 \mathrm{bpm}$ without consideration of fetal or maternal age, therefore, is questionable.
Mitral Valve Prolapse. Wiswell states that about $10 \%$ of childbearing-age women experience mitral valve prolapse (MVP). This problem seems to be aggravated at a heart rate above 140 bpm (Wiswell, 1991), thus, provides one rationale for ACOG's guidelines. However, there is some evidence to suggest that pregnancy per se may actually alleviate MVP (Raybund, LeMire, Bird, \& Buda, 1987). MVP is defined as a protrusion of the mitral leaflet into the left atrium during systole (Degani, Abinader, \& Scharf, 1989). Some cases can be diagnosed by an auscultatory method-hearing a systolic click or late systolic murmur. Other cases require an ECG in order to identify T-wave changes or angiographic findings of MVP (Degani, Abinader, \& Scharf, 1989; Raybund, LeMire, Bird, \& Buda, 1987).

The fact that the incidence of MVP is relatively low and the evidence that pregnancy may improve this condition (Raybund, LeMire, Bird, \& Buda, 1987) do not negate the potential risk of aggravating the condition by exercise. Unfortunately, there is a reasonable chance that nurses will encounter clients with asymptomatic and undiagnosed MVP. Only careful physical examination and thorough history assessment before advising exercise for pregnant women can decrease this risk.

Perceived Exertion Scales. Rating of perceived exertion (RPE) scales, which the ACSM's guidelines include (Figure 1), provide a method to quantify subjective exercise intensity (Borg \& Linderholm, 1967). The RPE scale, sometimes called Borg's scale, correlates closely with several exercise variables for nonpregnant subjects, including percent $\mathrm{VO}_{2}$ peak, percent heart rate reserve, minutes ventilation, and blood lactate levels (ACSM, 1991).

The RPE scale is a reproducible measure of exertion within a wide variety of people regardless of age. During most exercise testing, the RPE scale is an accurate gauge of impending fatigue in men. Most people rate the ventilatory threshold (60 to $70 \%$ $\mathrm{VO}_{2}$ maximum) as "somewhat hard" or "hard" (RPE 13 to 16) and reach the subjective limit of fatigue at an RPE of 18 to 19 ("very, very hard") (ACSM, 1991). The RPE scale has also been

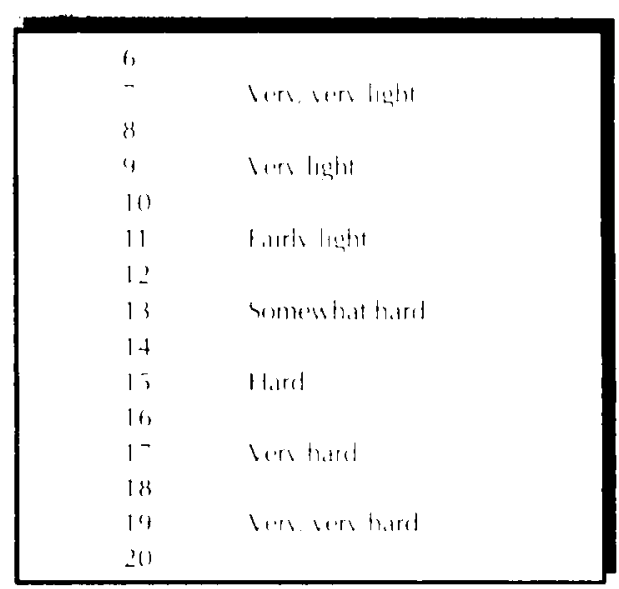

Note: The chart is cited from: Borg. C.A. (1982). Medical Science Sports Exercise. 14, 377-387.

Figure 1: Rating of Perceived Exertion Scale (RPE). Left column indicates scores. Right column indicates corresponding perceived exertion. 
shown to correlate with heart rate and METs as measures of exercise intensity. A MET is a way of expressing energy cost of activity. One MET is equivalent to $3.5 \mathrm{ml} \cdot \mathrm{Kg}^{-1} \mathrm{~min}^{-1}$, which in most people approximates their metabolic rate while sitting quietly. In the training of male subjects, the heart rate will approximate 130 to $160 \mathrm{bpm}$ for the typical exercise intensity range, or an RPE of 11 to 16 . The RPE of 11 to 16 will also reflect a relative exercise intensity from $50 \%$ to $75 \%$ of maximal METs.

However, Borg's scale was developed with male subjects using bicycle ergometers (ACSM, 1991) and may be inappropriate to assess the relative work intensity of pregnant women who may engage in various types of exercise.

Other exercise guidelines for pregnant women exist but will not be examined here. Fitness Canada and Fitness Ontario, for instance, are not commonly used in the United States.

Among the available guidelines, none account for gestational age in determining maximum exercise intensities (ACOG, 1985; ACSM, 1991; Fitness Canada, 1982; Fitness Ontario, 1983; Wolfe, et al., 1989). In fact, only the ACSM guidelines mention the need for considering gestation: "Target heart rate method may be used, but may require adjustments for progressive decline in maximal heart rate during pregnancy" (ACSM, 1991).

The available scientific information raises several questions about accuracy and relevance. Current guidelines are based on assumptions rather than on scientific knowledge, since little if any data has been systematically collected from studies of pregnant women.

The literature pertaining to pregnant women's exercise suggests a need to set limits on exercise based on the theory of cardiac output redistribution. Epidemiologic studies indicate that highly athletic women deliver lower birth weight babies. However, smaller infant size can only theoretically be attributed to reduced uterine blood flow and subsequent decrease in oxygen and nutrients available for the fetus. As described earlier, studies of uterine and umbilical arterial hemodynamics using Doppler waveform, sodium injection, or other methods in human beings have thus far given inconclusive results (Ballor, Beque, \& Katch, 1989; Hume, et al., 1990; Moore, Jarrett, \& Bendick, 1988; Moore, 1988; Morris, Osborn, Wright, \& Hart, 1956; Morrow, Knox, \& Bull 1989; Rauramo \& Forss, 1988, Steegers, et al., 1988; Veille, Bacevice, Wilson, Janos, \& Hellerstein, 1989).

Despite the lack of precise studies, several general guidelines follow. Pregnant women should be advised to avoid heat stress, particularly during early pregnancy. Heat stress can be decreased through adequate hydration, appropriate clothing, and the avoiding direct heat while exercising. Similarly, they should be encouraged to engage in short, frequent periods of exercise.

Pregnant women should sit or lie down after running or brisk walking. Standing may cause increased venous pooling due to pregnancy-related distension of leg veins (Bonds \& Papadoupoulos, 1985). Swimming may be emphasized as a choice of exercise because it should not cause potential venous pooling and hyperthermia and might even offer protection from these conditions. Slowly walking in a swimming pool may satisfy some women's needs for exercise.
Women who exercised regularly before pregnancy may find that losing the fitness they had obtained is extremely frustrating. Nurses and other healthcare providers should not underestimate a woman's desire for better fitness even, or particularly, during pregnancy. Physical activity in general is associated with an enhanced sense of well-being (Artal-Mittlemark \& Artal, 1991). Some studies report a correlation between regular physical exercise and a decrease in anxiety during pregnancy (Dishman \& Landy, 1988; Greist, Klein, Eischens, \& Faris, 1978), while others report that increased secretion of plasma beta-endorphin in pregnant women who exercise reduces pain perception during labor (Varrassi et al., 1989). Knowledge about the relationships between pregnant women's exercise and the process of labor, delivery, and birth outcome, as well as the unborn child's health after birth is needed. With a clearer understanding of the effect of exercise on maternal and fetal health, nurses will be able to provide specific exercise guidelines for pregnant women, as well as apply exercise as an intervention to promote maternal and fetal health. This increased understanding will enable nurses to more fully meet clients' health needs. Research is needed to determine the physiologic effect of maternal exercise among pregnant women with average fitness levels, which can serve as the basis for exercise guidelines for healthy pregnant women. $\Sigma \Theta T$

\section{References}

American College of Obstetricians and Gynecologists. (1985). Exercise during pregnancy and the postnatal period. In ACOG Technical Bulletin: Women and exercise, No, 87. Washington, DC: ACOG.

American College of Sports Medicine. (1991). Guidelines for exercise testing and prescription (4th ed.). Philadelphia: Lea \& Febiger.

Artal-Mittlemark, R.M., \& Posner, M.D. (1991). Exercise guidelines for pregnancy. In R.M. Artal-Mittelmark, R.A. Wiswell, \& B.L. Drinkwater (Eds.), Exercise in pregnancy (2nd ed., 213-224). Baltimore: Williams \& Wilkins.

Artal-Mittlemark, R.M., Wiswell, R.A., Drinkwater, B.L., \& Jones-Repovich, W.E. (1991). Exercise guidelines for pregnancy. In R.M. Artal-Mittelmark, R.A. Wiswell, \& B.L. Drinkwater (Eds.), Exercise in pregnancy (2nd ed., 299312). Baltimore: Williams \& Wilkins.

Artal-Mittelmark, R.M., Dorey, F.J., \& Kirschbaum, H. (1991). Effect of maternal exercise on pregnancy outcome. In R.M. Artal-Mittelmark, R.A Wiswell, \& B.L. Drinkwater (Eds.), Exercise in pregnancy (2nd ed., 225229). Baltimore: Williams \& Wilkins.

Artal-Mittelmark, M., \& Artal, R.A. (1991). Emotional aspects of exercise in pregnancy. In R.M. Artal-Mittelmark, R.A. Wiswell, \& B.L. Drinkwater (Eds.), Exercise in pregnancy (2nd ed., 287-297). Baltimore: Williams \& Wilkins.

Ballor, D.L., Beque, M.D., \& Katch, V. (1989). Energy output during hydraulic resistance circuit exercise for males and females. Journal of Applied Sport Science and Research, 3(1), 7-12.

Baumann, H., Huch, A., \& Huck, R. (1989). Doppler sonographic evaluation of exercise-induced blood flow velocity and waveform changes in fetal, uteroplacental and large maternal vessels in pregnancy women. Journal of Perinatal Medicine 17(4), 279-287.

Bonds, D., \& Delivoria-Papadoupoulos, M. (1985). Exercise during pregnancy. Potential fetal and placental metabolic effects. Annals of Clinical and Laboratory Science, 15(2), 91-99.

Borg, G., \& Linderholm, H. (1967). Perceived exertion and pulse rate during graded exercise in various age groups. Acta Medica Scandinavica, 472 (Suppl.), 194-206.

Brinkman, C.R. (1990). Circulation in the pregnant uterus. In M.E. Carsten \& J.D. Miller (Eds.), Uterine function: Molecular and cellular aspects (519539). New York: Plenum Press. 
Brown, C.H., Harrower, J.R., \& Deeter, M.F. (1972). The effects of crosscountry running on pre-adolescent girls. Medicine and Science in Sports, 4(1), 1-5.

Brown, C.H., \& Wilmore, J.H. (1974). The effects of maximal resistance training on the strength and body composition of women athletes. Medicine and Science in Sports, 6(3), 174-177.

Caldwell, F., \& Jopke, T. (1985). Questions and answers: ACSM 1985 Physician and Sports Medicine, 13, 145-148.

Campbell, S., Diaz-Recasens, J., Griffin, D.R., Cohen-Overbeek, T.E., Pearce, J.M., \& Willson, K. (1983). New Doppler technique for assessing uteroplacental blood flow, Lancet, $1(8326$ pt. 1), 675-677.

Chandler, K.D., \& Bell, A.W. (1981). Effects of maternal exercise on fetal and maternal respiration and nutrient metabolism in the pregnant ewe. Journal of Developmental Physiology, 3(3), 161-176.

Clapp, J.F., III. (1990). Theoretical and technical questions involved with hemodynamic responses [Letter to the editor]. American Journal of Obstetrics and Gynecology 162, 867-868.

Cunningham, F.G., MacDonald, P.C., \& Gant N.F. (1989). Williams obstetrics (18th ed.). Norwalk, CT: Prentis Hall/Appleton \& Lange.

Cunningham, L.N., \& Cantu, R.C. (1990). Acute and chronic effects of exercise using an Exercycle in healthy, untrained adults. Physical Therapy, 70(8), 494502.

Degani, S., Abinader, E.G., \& Scharf, M. (1989). Mitral valve prolapse and pregnancy: A review. Obstetrical and Gynecological Survey, 44(9), 642-649.

Dishman, R.K., \& Landy F.J. (1988). Psychological factors and prolonged exercise. In D.R. Lamb \& R. Murray (Eds.), Perspectives in exercise science and sports medicine: Prolonged exercise (Vol. 1, 281-350). Indianapolis, IN: Benchmark Press.

Drinkwater, B.L. (1973). Physiological responses of women to exercise. Exercise and Sport Sciences and Reviews, 1, 125-153.

Drinkwater, B.L., \& Artal-Mittelmark, R.M. (1991). Heat stress and pregnancy. In R.M. Artal-Mittelmark, R.A. Wiswell, \& B.L. Drinkwater (Eds.) Exercise in pregnancy (2nd ed., 261-270). Baltimore: Williams \& Wilkins.

Edward, M.J. (1986). Hyperthermia as a teratogen. Teratol Carcinog Mutagen, 6, 563-582

Erdely, G.J. (1962). Gynecological survey of female athletes. Journal of Sports Medicine and Physical Fitness, 2, 174-179.

Erskine, R.L.A., \& Ritchie, J.W.K. (1985). Quantitative measurement of fetal blood flow using Doppler ultrasound. British Journal of Obstetrics and Gynecology, 92(6), 600-604.

Fagard, R. (1985). Habitual physical activity, training, and blood pressure in normo- and hypertension. International Journal of Sports Medicine, 6(2), 57-67.

Fitness Canada. (1982). Fitness and pregnancy. Ottawa: Fitness Canada.

Fitness Ontario. (1983). Pre/post natal fitness. Toronto: Ontario Ministry of Tourism and Recreation, Sports and Fitness Branch.

Gledhill, N. (1985). The influence of altered blood volume and oxygen transport capacity on aerobic performance. Exercise and Sport Science Reviews, 13, 75-93.

Greist, J.H., Klein M.N., Eischens R.R., \& Faris J.T. (1978). Running out of depression. Sports Medicine, 6, 49-50.

Guyton, A.C. (1991). Textbook of medical physiology (8th ed.). Philadelphia: W.B. Saunders.

Guzman, C., \& Caplan, R. (1970). Cardiorespiratory response to exercise during pregnancy. American Journal of Obstetrics and Gynecology, 108, 600-605.

Hohimer, A.R., Bissonnette, J.M., Metcalfe, J., \& McKean, T.A. (1984). Effect of exercise on uterine blood flow in the pregnant Pygmy goat. American Journal of Physiology, 246 (2 pt. 2), H207-H212.

Hume, R.F., Bowie, J.D., McCoy, C., Magarelli, P.C., Gall, M., Hertzberg, B.S., Carroll, B.A., \& Killam, A.P. (1990). Fetal umbilical artery Dopple response to graded maternal aerobic exercise and subsequent maternal mean arterial blood pressure. American Journal of Obstetrics and Gynecology, $163,826-839$

Itskovitz, J. (1987). Maternal-fetal hemodynamics. In D. Maulik \& D. McNellis (Eds.), Doppler ultrasound measurement of maternal-fetal hemodynamics (13-42). Ithaca, NY: Perinatology Press.

Lotgering, F.K., Gilbert, R.D., \& Longo, L.D. (1983). Exercise responses in pregnant sheep: Oxygen consumption, uterine blood flow, and blood volume. Journal of Applied Physiology, 55(3), 834-841.
Lotgering, F.K., Gilbert, R.D., \& Longo, L.D. (1985). Maternal and fetal responses to exercise during pregnancy. Physiology Review, 65(1), 1-36.

McArdle, W.D., Katch, F.I., \& Katch, V.L. (1986). Exercise physiology: Energy, nutrition, and human performance (2nd ed.). Philadelphia: Lea \& Febiger.

Milewski, A., Ferguson, K.L., \& Terndrup, T.E. (1991). Comparison of pulmonary artery, rectal, and tympanic membrane temperatures in adult intensive care unit patients. Clinical Pediatrics, 30(4) (Suppl.), 13-16, 3435.

Miller, P., Smith, D.W., \& Shepard, T.H. (1978). Maternal hyperthermia as a possible cause of anencephaly. Lancet, 1, 519-521.

Moore, D.H., Jarrett, J.C., II, \& Bendick, P.J. (1988). Exercise-induced changes in uterine artery blood flow, as measured by Doppler ultrasound, in pregnant subjects. American Journal of Perinatology, 5(2), 94-97.

Moore, K.L. (1988). The developing human (4th ed.). Philadelphia: W.B. Saunders.

Morris, N., Osborn, S.B., Wright, H.P., \& Hart, A. (1956). Effective uterine blood flow during exercise in normal and preeclamptic pregnancies, Lancet, 2, 441-448.

Morrow, R.J., Ritchie, J.W., \& Bull, S.B. (1989). Fetal and maternal hemodynamic responses to exercise in pregnancy assessed by Doppler ultrasonography. American Journal of Obstetrics and Gynecology, 160(1), $138-140$

Plowman, S. (1974). Physiological characteristics of female athletes. Research Quarterly, 45(4), 349-362.

Rauramo, I., \& Forss, M. (1988). Effects of exercise on maternal hemodynamics and placental blood flow in healthy women. Acta Obstetrica Gynecologica Scandinavica, 67(1), 21-25.

Raybund, W.F., LeMire, M.S., Bird, J.L., \& Buda, A.J. (1987). Mitral valve prolapse: Echocardiographic changes during pregnancy. Journal of Reproductive Medicine, 32(3), 185-187

Sady, S.P., Carpenter, M.W., Sady, M.A., Haydon, B., Hoegsberg, B., Cullinane, E.M., Thompson, P.D., \& Coustan, D.R. (1988). Prediction of VO max during cycle exercise in pregnant women. Journal of Applied Physiology, 65(2), 657-661.

Sady, S.P., Carpenter, M.W., Thompson, P.D., Sady, M.A., Haydon, B., \& Coustan, D.R. (1989). Cardiovascular response to cycle exercise during and after pregnancy. Journal of Applied Physiology, 66, 336-341

Shiota, K. (1982). Neural tube defects and maternal hyperthermia in early pregnancy. American Journal of Medical Genetics, 12(3), 281-288.

Steegers, E.A.P., Buunk, G., Binkhorst, R.A., Jongsma, H.W., Wijn, P.F.F. \& Hein, P.R. (1988). The influence of maternal exercise on the uteroplacental vascular bed resistance and fetal heart rate during normal pregnancy. European Journal of Obstetrics, Gynecology, and Reproductive Biology, 27(1), 21-26.

Thompson, R.S., Trudinger, B.J., \& Cook, C.M. (1988). Doppler ultrasound waveform indices: $\mathrm{A} / \mathrm{B}$ ratio, pulsatility index and Pourcelot ratio. British Journal of Obstetrics and Gynecology, 95(6), 581-588.

Varrassi, G., Bazzano, C., \& Edwards W.T. (1989). Effects of physical activity or maternal plasma b-endorphi levels and perception of labor pain. American Journal of Obstetrics and Gynecology, 160, 707-712.

Veille, J.C., Bacevice, A.E., Wilson, B., Janos, J., \& Hellerstein, H.K. (1989). Umbilical artery waveform during bicycle exercise in normal pregnancy. Obstetrics and Gynecology 73, 57.

Wallace, J.P., \& Wiswell, R.A. (1991). Maternal cardiovascular response to exercise during pregnancy. In R.M. Artal-Mittelmark, A. Wiswell, \& B.L. Drinkwater (Eds.), Exercise in pregnancy (2nd ed., 195-206). Baltimore: Williams \& Wilkins.

Wiswell, R.A. (1991). Exercise physiology. In R.M. Artal-Mittelmark, R.A. Wiswell, \& B.L. Drinkwater (Eds.), Exercise in pregnancy (2nd ed., 195206). Baltimore: Williams \& Wilkins.

Wiswell, R.A., Artal-Mittelmark, R., Romen, Y., Kammula, R., \& Dorey, F. (1985). Hormonal and metabolic response to maximal exercise in pregnancy. Medicine and Science in Sports and Exercise, 17, 206

Wolfe, L.A., Hall, P., Webb, K.A., Goodman, L., Monga, M., \& McGrath, M.J. (1989). Prescription of aerobic exercise during pregnancy. Sports Medicine, 8(5), 273-301 